\title{
Poly(acrylonitrile) Chains in Zeolite Channels: Polymerization and Pyrolysis
}

\author{
Patricia Enzel and Thomas Bein ${ }^{*}+$ \\ Department of Chemistry, Purdue University, West Lafayette, Indiana 47907
}

Received December 10, 1991. Revised Manuscript Received March 10, 1992

\begin{abstract}
Acrylonitrile was adsorbed into the dehydrated forms of different large- and medium-pore zeolites and polymerized with radical initiators. On saturation, 46,6, and 9 molecules of acrylonitrile per unit cell were adsorbed from the gas phase into dehydrated zeolite $\mathrm{NaY}, \mathrm{Na}$-mordenite, and silicalite, respectively. Reaction with an aqueous solution of $\mathrm{K}_{2} \mathrm{~S}_{2} \mathrm{O}_{8}$ and $\mathrm{NaHSO}_{3}$ produced poly (acrylonitrile), of which $30 \%$ based on the monomer loading was recovered from $\mathrm{NaY}, 18 \%$ from mordenite, and no polymer was found in silicalite. The channel diameter of silicalite is too small to allow the polymerization to proceed. The intrazeolite polymer could be recovered after dissolution of the host with dilute aqueous HF and was shown to be very similar to bulk poly(acrylonitrile), using IR and NMR spectroscopies. Chain length analysis with gel permeation chromatography revealed a peak molecular weight of 19000 for poly(acrylonitrile) recovered from the $\mathrm{NaY}$ host and about 1000 for the polymer recovered from mordenite. The intrazeolite poly(acrylonitrile) (PAN) was pyrolyzed under nitrogen, resulting in a black encapsulated material that has lost the nitrile groups and hydrogen. Complete graphitization $(\mathrm{N} / \mathrm{C}$ atomic ratio zero) with formation of extended sheetlike structures is not possible in the zeolite for steric reasons; instead, the intrazeolite pyrolysis reactions at 650 and $700^{\circ} \mathrm{C}(\mathrm{N} / \mathrm{C}$ atomic ratios 0.20 and 0.18 , respectively) are apparently limited to the ladder structures formed in the bulk at lower temperature, at ca. $530^{\circ} \mathrm{C}$. Thermal analyses under nitrogen of the zeolite-acrylonitrile inclusions show that the zeolite host drastically changes the pyrolysis reactions. In contrast to bulk PAN that loses weight rapidly above $260^{\circ} \mathrm{C}$, accompanied by a sharp exotherm at this temperature, the zeolite inclusions show a much less defined onset of decomposition with a broad exotherm. After recovery from the zeolite hosts, the pyrolyzed poly(acrylonitrile) shows electronic dc conductivity at the order of $10^{-5} \mathrm{~S} \mathrm{~cm}^{-1}$.
\end{abstract}

\section{Introduction}

Interest in the understanding of electronic conductivity at nanometer dimensions increases rapidly. Studies of the conduction mechanism of conjugated polymers ${ }^{1-3}$ would benefit substantially if the low-dimensional structures were available as decoupled, structurally well-defined entities. Furthermore, the design of nanometer-size conducting structures with modified electronic properties could potentially reduce the size of electronic circuitry to molecular dimensions. ${ }^{4,5}$

We have recently demonstrated the encapsulation of conjugated polymers such as polypyrrole, polyaniline, and polythiophene in the crystalline channel systems ${ }^{6}$ of zeolites. ${ }^{7}$ Precursor monomers are introduced into the zeolite host and are subsequently polymerized by appropriate oxidants in the pore system. The synthesis of these and related systems represents an important step towards stabilized and oriented molecular wires, that could in principle allow to process signals or to store information inside channel systems with nanometer dimensions.

Encapsulation of Conducting Polymers in Host Systems. With the goal of achieving molecular alignment of conjugated polymer chains and thus potentially higher carrier mobilities, several groups have designed routes to either synthesize the polymers in ordered systems, such as liquid crystals, ${ }^{8}$ or encapsulate conjugated polymeric chains inside crystalline inorganic host materials by in situ polymerization.

Polypyrrole and polythiophene fibers of only $30 \mathrm{~nm}$ in width have been grown electrochemically within microporous membranes, such as Anopore alumina filtration membranes. ${ }^{9}$ The higher conductivity of these fibers was associated with the high degree of orientation of the polymers along the fiber axis.

\footnotetext{
* Author for correspondence.

${ }^{\dagger}$ Previous address: Department of Chemistry, University of New Mexico, Albuquerque, NM 87131.
}

Pyrrole, thiophene, and aniline were intercalated and in situ polymerized in the interlayer space of iron oxychloride $(\mathrm{FeOCl}){ }^{10}$ Similarly, in situ intercalative polymerization of pyrrole in layered vanadium oxide $\left(\mathrm{V}_{2} \mathrm{O}_{5} \cdot n \mathrm{H}_{2} \mathrm{O}\right)$ resulted in a material in which the conductive polymer is inserted in the interlayer space of the inorganic solid. ${ }^{11}$ Polyaniline intercalates were formed by polymerization of aniline in the galleries of $\mathrm{Cu}$-exchanged fluorohectorite. ${ }^{12}$ Gallery $\mathrm{Cu}^{\mathrm{II}}$ ions served as the oxidation centers. The as-synthesized polymer is insulating but becomes conducting after exposure to $\mathrm{HCl}$ vapors, with

(1) Proceedings of the International Conference on Science and Technology of Synthetic Metals, ICSM'88 and '90; Synth. Met. 1988, 28 (1-3) and 29 (1); Synth. Met. 1991, 41-43.

(2) Handbook of Conducting Polymers; Skotheim, T. A., Ed.; Marcel Dekker: New York, 1986; Vol. 1.

(3) Conducting Polymers. Special Applications; Alcacer, L., Ed.; D. Reidel: Dordrecht, 1987.

(4) Hopfield, J. J.; Onuchic, J. N.; Beratan, B. N. Science 1988, 241, 817.

(5) (a) Molecular Electronic Devices; Carter, F. L., Ed.; Marcel Dekker: New York, 1982. (b) Molecular Electronic Devices II; Carter, F. L., Ed.; Marcel Dekker: New York, 1987.

(6) Breck, D. W. Zeolite Molecular Sieves; R. E. Krieger Publishing Co.: Malabar, FL, 1984

(7) (a) Enzel, P.; Bein, T. J. Phys. Chem. 1989, 93, 6270. (b) Enzel, P.; Bein, T. J. Chem. Soc., Chem. Commun. 1989, 1326. (c) Bein, T.; Enzel, P. Angew. Chem., Int. Ed. Engl. 1989, 28, 1692. (d) Bein, T.; Enzel, P. Mol. Cryst. Liq. Cryst. 1990, 181, 315. (e) Bein, T.; Enzel, P.; Beuneu, F.; Zuppiroli, L. Inorganic Compounds with Unusual Properties III. Electron Transfer in Biology and the Solid State; Johnson, M. K., et al., Eds.; ACS Adv. Chem. Ser. 1990, No. 226, 433 .

(8) Aldissi, M. J. Polym. Sci., Polym. Lett. Ed. 1985, 23, 167.

(9) Cai, Z.; Martin, C. R. J. Am. Chem. Soc. 1989, 111, 4138.

(10) (a) Kanatzidis, M. G.; Tonge, L. M.; Marks, T. J.; Marcy, H. O.; Kannewurf, C. R. J. Am. Chem. Soc. 1987, 109, 3797. (b) Kanatzidis, M. G.; Marcy, H. O.; McCarthy, W. J.; Kannewurf, C. R.; Marks, T. Solid State Ionics 1989, 32/33, 594. (c) Kanatzidis, M. G.; Wu, C.-G.; Marcy, H. O.; Kannewurf, C. R.; Kostikas, A.; Papaefthymiou, V. Adv. Mater. $1990,2,364$.

(11) Kanatzidis, M. G.; Wu, C.-G.; Marcy, H. O.; Kannewurf, C. R. J. Am. Chem. Soc. 1989, 111, 4139 .

(12) Mehrotra, V.; Giannelis, E. P. In Polymer Based Molecular Composites, MRS Symp. Proc.; Schaefer, D. W., Mark, J. E., Eds.; MRS: Pittsburgh, 1990; p 171 . 
in-plane conductivity values of $0.05 \mathrm{~S} \mathrm{~cm}$.

Pyrrole has been spontaneously oxidized and in situ polymerized in channels of the three-dimensional coordination polymer $\left[\left(\mathrm{Me}_{3} \mathrm{Sn}\right)_{3} \mathrm{Fe}^{\mathrm{III}}(\mathrm{CN})_{6}\right]_{\infty}{ }^{13}$ The oxidizing agents are the $\mathrm{Fe}^{\mathrm{III}}$ ions in the lattice. The oligomeric/ polymeric pyrrole chains are hosted within parallel channels with a cross section of $6.8 \AA$.

The catalytic formation of trans-polyacetylene on the exterior surfaces of $\mathrm{Co}^{\mathrm{II}}$ - and $\mathrm{Ni}^{\mathrm{II}}$-exchanged zeolites has been demonstrated. ${ }^{14}$ Methylacetylene gas reacts with the acid sites in zeolites $\mathrm{L}, \mathrm{Y}, \beta, \mathrm{ZSM}-5, \omega$, mordenite, and SAPO-5 to form reactive, conjugated oligomers. ${ }^{15}$ Porefilling measurements and lattice expansion show that the reaction occurs within the zeolite pores. Short-chain oligomers of polythiophene were prepared, oxidatively doped to the conducting state, and stabilized in $\mathrm{Na}$-pentasil zeolites. ${ }^{16}$ It was found that the presence of aluminum in the zeolite framework is essential to observe oxidation.

The electronic properties of the encapsulated single chains of conjugated polymers as a function of structure and interactions with the host are of particular interest. In the first physical study of spin and charge carriers in zeolite-encapsulated polypyrrole, ${ }^{17}$ we find that although the chains are fully oxidized and contain bipolaronic charge carriers, they do not exhibit significant ac conductivity at $1 \mathrm{GHz}$. This observation as well as the relatively large line width of the ESR signal can be explained with trapping of polarons and bipolarons by the periodic zeolite framework.

Intrazeolite Encapsulation of Poly(acrylonitrile) and Its Pyrolysis Products. The above finding, although limited to the polypyrrole system at this point, suggests that carrier mobility might be strongly influenced by electrostatic interactions between the conjugated polymer chains and the host channels. It is therefore of great interest to explore the encapsulation of noncharged polymers in zeolites and the electronic properties of the resulting structures.

Our first candidate for this approach is pyrolyzed ${ }^{18}$ poly(acrylonitrile) (PAN), a well-known material that can be formed as thin films and fibers. Polymerization of acrylonitrile proceeds rapidly and exothermically in the presence of free radicals or anionic initiators. ${ }^{19}$ Pyrolysis of PAN leads to the formation of a ladder polymer by cyclization through the nitrile pendant group, as shown by IR and solid-state ${ }^{13} \mathrm{C}$ NMR studies. ${ }^{20}$ With increasing pyrolysis temperature, a graphite-like structure is formed, in which the delocalized electrons contribute to the electrical conductivity. ${ }^{21}$ The conductivity increases with pyrolysis temperature owing to an increased degree of graphitization. ${ }^{22}$ The polymerization of acrylonitrile in montmorillonite ${ }^{23}$ and of aminoacetonitrile in layered

(13) Brandt, P.; Fischer, R. D.; Martinez, E. S.; Calleja, R. D. Angew. Chem., Int. Ed. Engl. 1989, 28, 1265.

(14) Dutta, P. K.; Puri, M. J. Catal. 1988, 111, 453.

(15) Cox, S. D.: Stucky, G. D. J. Phys. Chem. 1991, 95, 710.

(16) Caspar, J. V.; Ramamurthy, V.; Corbin, D. R. J. Am. Chem. Soc. $1991,113,600$

(17) Zuppiroli, L.; Beuneu, F.; Mory, J.; Enzel, P.; Bein, T. Phys. Rev. Lett., submitted.

(18) Berlin A A J Polym. Sci. 1961, 55,621.

(19) Encyclopedia of Polymer Science and Engineering; Mark, H. F., Bikales, N., Overberger, C. G., Menges, G., Kroschwitz, J. I., Eds.; Wiley: New York, 1985; Vol. 1,

(20) Stevenson, W. T. K. Garton, A. Ripmeester, J A * Wiles, D. M. Polym. Deg. Stab. 1986, 15, 125.

(21) (a) Bailey, J. E.; Clarke, A. J. Nature 1971, 234, 529. (b) Goodhew, P. J.; Clarke, A. J.; Bailey, J. E. Mater. Sci. Eng. 1975, 17, 3 (22) Renschler, C. L.; Sylwester, A. P.; Salgado, L. V. J. Mater. Res. $1989,4,452$.

(23) Sonobe, N.; Kyotani, T.; Hishiyama, Y.; Shiraishi, M.; Tomita, A. J. Phys. Chem. 1988, 92, 7029.
1. Adsorption of acrylonitrile in dry zeolite $Y$

2. Intrazeolite radical polymerization
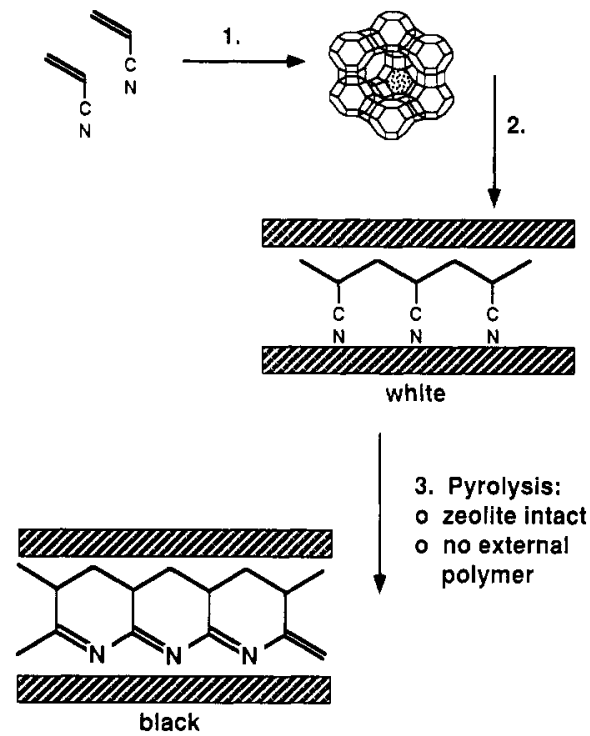

Figure 1. Intrazeolite polymerization of acrylonitrile.

metal phosphates ${ }^{24}$ has been reported, but these systems contain sheets of macroscopic dimensions different from the nanometer channels of the zeolite hosts.

This article describes the assembly of poly(acrylonitrile) (PAN) strands in different large-pore zeolites, zeolite $\mathrm{Y}$ and mordenite, and explores the pyrolysis reactions of the encapsulated polymer (Figure 1). Zeolite $\mathrm{Y}$ is composed of sodalite cages ( $2.5 \AA$ windows), interconnected by double six-rings of $\mathrm{Si} / \mathrm{Al}$, and of "supercages" with $8 \AA$ windows which together form a three-dimensional open framework with typical unit cell composition $\mathrm{Na}_{56} \mathrm{Al}_{56} \mathrm{Si}_{136} \mathrm{O}_{384}$, and mordenite features pseudo-one-dimensional 12-ring channels, with basic unit cell composition $\mathrm{Na}_{8} \mathrm{Al}_{8} \mathrm{Si}_{40} \mathrm{O}_{96}$. Silicalite of composition $\mathrm{SiO}_{2}$ offers intersecting zigzag and straight channels with pore openings of about $5.5 \AA$ diameter.

As discussed below, the intrazeolite PAN, when pyrolyzed in nitrogen, produces a black encapsulated material similar to the pyrolysis products obtained from bulk PAN. After recovery from the zeolite host, the pyrolyzed material shows electrical conductivity in the semiconductor regime. These structures are fundamentally different from polypyrrole and the other above-mentioned polymers because they are not charged; thus, the degree of coupling to the host channels is expected to be drastically reduced. This should make these materials interesting candidates for intrazeolite conducting systems.

\section{Experimental Part}

Sample Preparation. NaY (LZY-52), Na-mordenite (LZ-M5), and silicalite (S-115) were generously donated by the Union Carbide Corp. The zeolites were equilibrated with water vapor in a desiccator with a saturated $\mathrm{NH}_{4} \mathrm{Cl}$ solution for at least a week. The zeolites were degassed under oxygen flow by heating at 1 ${ }^{\circ} \mathrm{C} / \mathrm{min}$ to $100^{\circ} \mathrm{C}$, for $10 \mathrm{~h}$ at $100^{\circ} \mathrm{C}$, at $1^{\circ} \mathrm{C} / \mathrm{min}$ to $400^{\circ} \mathrm{C}$, and at $400^{\circ} \mathrm{C}$ for $8 \mathrm{~h}$ (last $4 \mathrm{~h}$ under vacuum). Dimethylformamide (Aldrich, HPLC grade) was used as received. Acrylonitrile was handled in an inert drybox. The inhibitor present in acrylonitrile was removed with an inhibitor remover column (Aldrich). Bulk poly(acrylonitrile) was synthesized from acrylonitrile with a redox initiator. ${ }^{25}$ To $150 \mathrm{~mL}$ of deaerated deionized water containing

(24) Pillion, J. E.: Thompson, M. E. Chem. Mater. 1991, 3, 777.

(25) Sorenson, W. R.; Campbell, T. W. Preparative Methods in Polymer Chemistry, 2nd ed.; Wiley-Interscience: New York, 1968. 
Table I. Intrazeolite Polymerization of Acrylonitrile

\begin{tabular}{lcccc}
\hline zeolite & $\begin{array}{c}\text { monomer } \\
\text { per unit cell }\end{array}$ & $\begin{array}{c}\text { monomer } / \mathrm{g} \text { of } \\
\text { zeolite, mol }\end{array}$ & $\begin{array}{c}\mathrm{K}_{2} \mathrm{~S}_{2} \mathrm{O}_{8}, \\
\text { mol }\end{array}$ & $\begin{array}{c}\mathrm{NaHSO}_{3} \\
\text { mol }\end{array}$ \\
\hline $\mathrm{NaY}$ & 46 & $3.40 \times 10^{-3}$ & $9.18 \times 10^{-6}$ & $1.19 \times 10^{-5}$ \\
NaMOR & 6 & $1.96 \times 10^{-3}$ & $5.25 \times 10^{-6}$ & $6.86 \times 10^{-6}$ \\
silicalite & 9 & $1.60 \times 10^{-3}$ & $4.37 \times 10^{-6}$ & $5.60 \times 10^{-6}$
\end{tabular}

Table II. Pyrolysis Treatments for Zeolite-PAN Samples

\begin{tabular}{|c|c|c|c|}
\hline sample & $\begin{array}{c}\text { pyrolysis } T \text {, } \\
{ }^{\circ} \mathrm{C}\end{array}$ & $\begin{array}{c}\text { pyrolysis } \\
\text { time, } \mathrm{h}\end{array}$ & atmosphere \\
\hline \multirow[t]{4}{*}{$\mathrm{NaY}-\mathrm{PAN}$} & 650 & 12 & $\begin{array}{l}\text { nitrogen } \\
\text { vacuum }\end{array}$ \\
\hline & & 24 & $\begin{array}{l}\text { nitrogen } \\
\text { vacuum }\end{array}$ \\
\hline & 700 & 12 & $\begin{array}{l}\text { nitrogen } \\
\text { vacuum }\end{array}$ \\
\hline & & 24 & nitrogen \\
\hline NaMOR-PAN & 800 & 12 & nitrogen \\
\hline
\end{tabular}

$11 \mathrm{~g}$ of acrylonitrile $(0.207 \mathrm{~mol})$ at $40^{\circ} \mathrm{C}$ were added under continuous stirring $0.15 \mathrm{~g}$ of potassium peroxodisulfate $(5.5 \mathrm{mmol})$ in $1 \mathrm{~mL}$ of water and $0.075 \mathrm{~g}$ of sodium bisulfite $(7.2 \mathrm{mmol})$ in $1 \mathrm{~mL}$ of water. A white precipitate appeared almost immediately. The reaction was continued for $3 \mathrm{~h}$. After that period, the precipitate was filtered off, washed with water, and dried.

Loading of Zoolite Crystals with Acrylonitrile Vapor. A known amount of zeolite, typically $500 \mathrm{mg}$, was loaded in the inert drybox into a quartz bucket. The quartz bucket was inserted into a quartz reactor and connected to a vacuum line $\left(10^{-5} \mathrm{Torr}\right)$. After pumping separately the quartz reactor containing the zeolite and the monomer liquid (freeze-pump-thaw cycles were applied to degas the monomer), acrylonitrile vapor from the liquid kept at $-8^{\circ} \mathrm{C}(\mathrm{KCl} /$ ice) was allowed to equilibrate for $1 \mathrm{~h}$ with the zeolite at room temperature. The excess of monomer was pumped of by evacuating the sample for $1 \mathrm{~h}$. The quartz bucket was weighed again in the drybox, and the amount of monomer loaded was then calculated.

Intrazeolite Acrylonitrile Polymerization. A 1-g sample of acrylonitrile-containing zeolite was suspended in $20 \mathrm{~mL}$ of deaerated water at $40^{\circ} \mathrm{C}$; to that suspension were added aqueous solutions of potassium peroxodisulfate $(0.01 \mathrm{M})$ and sodium bisulfite $(0.025 \mathrm{M})$ to obtain the amounts (in moles) listed in Table I. The zeolite suspensions were stirred for $12 \mathrm{~h}$, filtered off, and washed with deionized water.

Dissolution of the Framework To Recover the Intrazeolite Polymer. The zeolite frameworks were dissolved with a $25 \%$ aqueous solution of $\mathrm{HF}$. Generally, 1-3g of zeolite polymer were stirred in a Nalgene bottle with $25 \mathrm{~mL}$ of $25 \%$ aqueous solution of HF. After approximately 20-30 min all the zeolite was dissolved leaving some polymer suspended in solution. The polymer was filtered off, washed with copious amounts of deionized water, and dried.

Pyrolysis of Zeolite-PAN Samples. The zeolite/PAN adducts were loaded into quartz boats in a quartz tube reactor that was heated in a tube furnace. The samples were heated to target temperatures with a heating rate of $2^{\circ} \mathrm{C} / \mathrm{min}$. The target temperature was held for $12-24 \mathrm{~h}$. After that time the samples were cooled and analyzed. These treatments were done under nitrogen flow or vacuum. Table II summarizes the pyrolysis treatments.

Characterization. IR spectra of the samples were measured using $\mathrm{KBr}$ pellets in a Mattson Polaris instrument at $4-\mathrm{cm}^{-1}$ resolution and were analyzed with the ICON and the First software. Electronic absorption spectra of powders, covering the region between 240 and $2600 \mathrm{~nm}$, were measured on an Hitachi U3501 instrument with integrating sphere. The powder samples were dispersed in a custom-designed cell and covered with a quartz window. The spectra were measured against barium sulfate as reference. ${ }^{1} \mathrm{H}$ NMR and ${ }^{13} \mathrm{C}$ NMR spectra of polymer solutions were measured with a Bruker AC 250 spectrometer. Polyacrylonitrile was dissolved in DMSO- $d_{6}$ or DMF- $d_{7}$.

A poly(acrylonitrile) broad standard (Aldrich) with $M_{w}$ of 86,000 and $M_{\mathrm{n}}$ of 23000 was used for gel permeation chromatography. The molecular weight measurements were performed on a Waters gel permeation chromatograph equipped with a Model 510 pro-

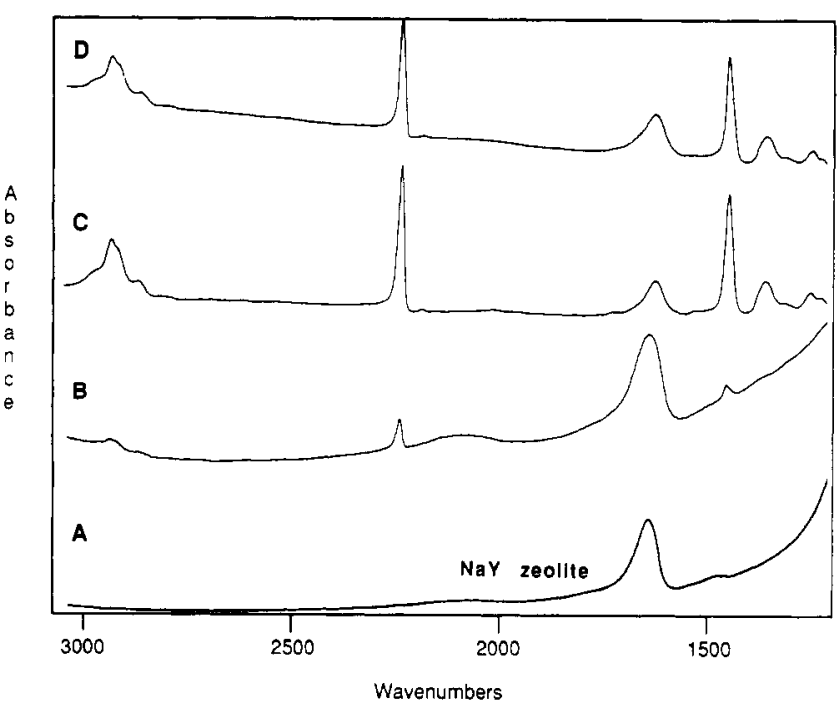

Figure 2. FTIR spectra of PAN samples: (A) NaY zeolite; (B) NaY-PAN inclusion; (C) bulk PAN; (D) PAN extracted from $\mathrm{NaY}-\mathrm{PAN}$ inclusion.

grammable solvent delivery module, two Shodex $\mathrm{KD}$ linear columns in series (802.5 and 804), and a differential refractometer. Approximately $0.1 \mathrm{wt} \%$ solutions of the PAN in DMF were prepared and filtered through a $0.5-\mu \mathrm{m}$ filter. The temperatures of the GPC columns and detector were maintained isothermally at $50^{\circ} \mathrm{C}$. The flow rate was $1 \mathrm{~mL} / \mathrm{min}$.

Dc conductivity measurements were carried out at room temperature with thin-pressed wafers (typically $0.5 \mathrm{~mm}$ thin) of the bulk polymers, zeolite polymer powders, and the extracted polymers, using the four-point technique. ${ }^{26}$

Thermogravimetric analyses of the polyacrylonitrile samples were performed at the UNM Center of Microengineered Ceramics, with an STA 1500 instrument from PL Thermal Sciences. Approximately $8 \mathrm{mg}$ of sample was used. The heating rate was 2 ${ }^{\circ} \mathrm{C} / \mathrm{min}$ from room temperature to $700^{\circ} \mathrm{C}$; the carrier gas was ultrahigh-purity nitrogen.

\section{Results and Discussion}

Formation of Intrazeolite Poly(acrylonitrile). Effect of the Host Framework. Table I shows the extent of loading with acrylonitrile vapor for the different zeolite hosts. The loadings correspond to saturation at room temperature with subsequent pumping under high vacuum. In zeolite Y, 46 molecules of acrylonitrile are loaded per unit cell, 6 in mordenite, and 9 in silicalite. However, even though the monomers adsorb into silicalite, no polymerization is observed within this host. The diameter of its channel system of approximately $5.5 \AA$ may be too small for the diffusion of radical initiator into the zeolite. Additionally, it is known that the polar nitrile groups in poly(acrylonitrile) exert intramolecular repulsion, forcing the molecules into an irregular helical conformation, which fits into a cylinder of about 6 - $\AA$ diameter. ${ }^{27}$ The spatial requirements of poly (acrylonitrile) could therefore preclude its formation in the channels of silicalite.

Recovery and Characterization of Intrazeolite PAN. The zeolite frameworks were dissolved with an aqueous solution of HF $(25 \%)$ to recover the intrazeolite polymer. Poly(acrylonitrile) is not damaged by this treatment as demonstrated by FTIR and NMR data.

Infrared spectra of the zeolite/polymer inclusions and of PAN extracted from the zeolites show peaks characteristic of the bulk polymer ${ }^{28,29}$ (Figure 2). The bands at

(26) Smits, F. M. Bell Syst. Tech. J. 1958, 710.

(27) Henrici-Olive, G.; Olive, S. Adv. Polym. Sci. 1979, 33, 123.

(28) Coleman, M. M.; Petcavich, R. J. J. Polym. Sci., Phys. Ed. 1978, 16,821 . 

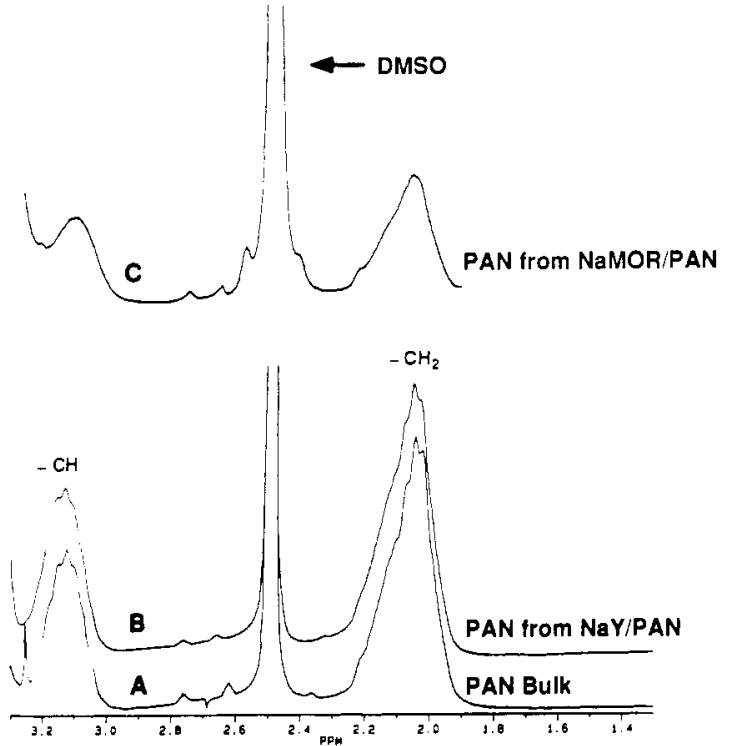

Figure 3. ${ }^{1} \mathrm{H}$ NMR spectra of PAN samples: (A) PAN bulk; (B) PAN extracted from NaY-PAN; (C) PAN extracted from $\mathrm{Na-}$ MOR-PAN.

2940 and at $2869 \mathrm{~cm}^{-1}$ are assigned to the methylenic $\mathrm{C}-\mathrm{H}$ stretching vibrations of the backbone, while the band at $2240 \mathrm{~cm}^{-1}$ is assigned to the pendant nitrile group. Additionally, the band at $1450 \mathrm{~cm}^{-1}$ is characteristic of methylenic deformation, and the band at $1368 \mathrm{~cm}^{-1}$ corresponds to the $\mathrm{C}-\mathrm{H}$ bending of methine in the polymer. The spectra of the extracted intrazeolite polymers are indistinguishable from the spectrum of the bulk polymer. It can be concluded that the polymer formed in the zeolites is poly(acrylonitrile).

${ }^{1} \mathrm{H}$ and ${ }^{13} \mathrm{C}$ NMR spectra of the recovered poly(acrylonitrile) extracted from zeolite $\mathrm{Y}$ and from NaMOR in DMSO- $d_{6}$ and DMF- $d_{7}$ are identical to that of PAN bulk (Figure 3). The ${ }^{1} \mathrm{H}$ NMR spectra show two broad bands at a ratio of 2 to 1 , one at $2.0 \mathrm{ppm}$ corresponding to the methylenic group in the polymer, and the other at $3.1 \mathrm{ppm}$ in agreement with a methine group. The methylene peak at $2 \mathrm{ppm}$ has been studied extensively regarding the stereoregularity of PAN. ${ }^{30}$ The ratios of syndiotactic to isotactic units were estimated to be about 50:50, indicating random configurations. The similarity of the shape of this peak in PAN extracted from the zeolites, bulk PAN, and PAN synthesized in an urea clathrate canal ${ }^{31}$ suggests the same structure for polymer formed in the zeolite as in the bulk. The ${ }^{13} \mathrm{C}$ NMR data of the zeolite-extracted PAN are also identical to those of the bulk material: $27.5\left(\mathrm{CH}_{2}\right)$, $32.7(\mathrm{CH})$, and $120.1 \mathrm{ppm}(-\mathrm{CN})$.

Chain Length of Intrazeolite Poly(acrylonitrile). The molecular weight of the polymer extracted from the zeolites was determined with gel permeation chromatography relative to a PAN broad standard. The complex molecular weight distribution curves are shown in Figure 4. For PAN extracted from $\mathrm{NaY}$, a peak molecular weight of 19000 is observed, corresponding to about 360 monomer units. If a spacing of $5.5 \AA /$ monomer is assumed in an extended polymer, the chain will have a length of about $0.2 \mu \mathrm{m}$, the same order of magnitude as the size of a zeolite crystal $(\sim 1 \mu \mathrm{m})$. An additional shoulder is detected at lower molecular weight. In $\mathrm{Na}$-mordenite, two groups of

(29) Chung, T.-C.; Schlesinger, Y.; Etemad, S.; MacDiarmid, A. G Heeger, A. J. J. Polym. Sci. Phys. Ed. 1984, 22, 1239.

(30) Svegliado, G.; Talamini, G.; Vidotto, G. J. Polym. Sci. A-1 1967, 5,2875 .

(31) Yamadera, R.; Murano, M. J. Polym. Sci. A-1 1967, 5, 1059.

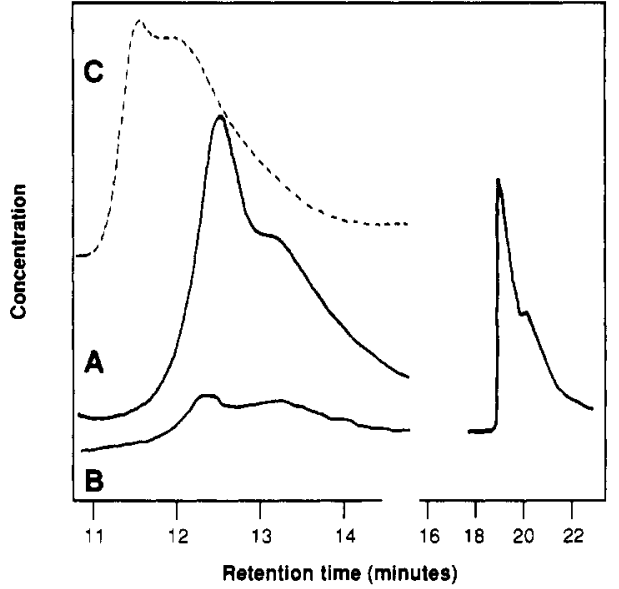

Figure 4. Molecular weight distribution curves for PAN samples obtained from gel permeation chromatography: (A) PAN extracted from NaY-PAN; (B) PAN extracted from NaMOR-PAN; (C) PAN broad standard $\left(M_{\mathrm{w}}=86000, M_{\mathrm{n}}=23000\right)$.

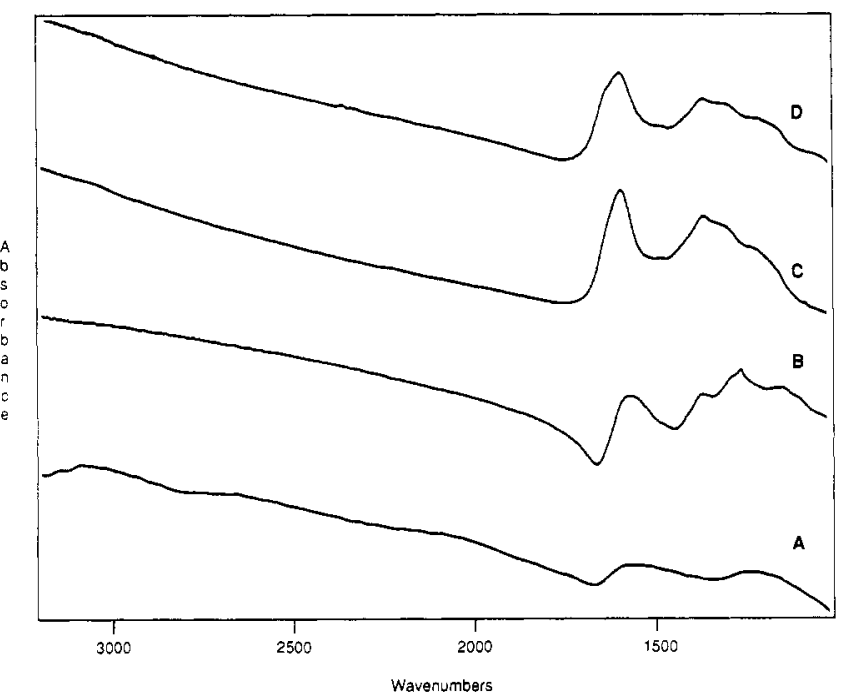

Figure 5. FTIR spectra of pyrolyzed PAN samples: (A) pyrolyzed bulk PAN $\left(650^{\circ} \mathrm{C}\right)$; (B) pyrolyzed bulk PAN $\left(530^{\circ} \mathrm{C}\right)$; (C) pyrolyzed PAN extracted from NaY-PyrPAN $\left(650^{\circ} \mathrm{C}, 12 \mathrm{~h}\right.$ vacuum); (D) pyrolyzed PAN extracted from $\mathrm{NaY}$-PyrPAN (700 ${ }^{\circ} \mathrm{C}, 24 \mathrm{~h}$ nitrogen).

two peaks are observed; a smaller fraction with a peak molecular weight of ca. 19000 and a larger fraction with molecular weight close to 1000 . This large fraction corresponds to about 20 monomers in the chain, about 0.01 $\mu \mathrm{m}$ long in a fully extended form, significantly shorter than the length of the zeolite crystal. For both hosts, the distributions at the high molecular weight end are quite similar. This could originate from similar pore diameters of the hosts, but details of the polymerization mechanism are not known in these systems. A small fraction, invisible in electron micrographs (see below) may reside at the exterior of the zeolite crystals. The difference in length for the polymers formed in zeolite $\mathrm{Y}$ and mordenite is an indication that the one-dimensional channel system in mordenite limits the extent of polymerization. This lim. itation could be associated with diffusional constraints or defects in the mordenite crystals that would limit the length of uninterrupted channels.

Pyrolysis of Intrazeolite PAN. With pyrolysis, the zeolites changed color from white to gray-black. X-ray powder diffraction data demonstrate that the zeolite framework remains intact even after pyrolysis treatments at $700^{\circ} \mathrm{C}$ for $\mathrm{NaY}$. Scanning electron micrographs show 


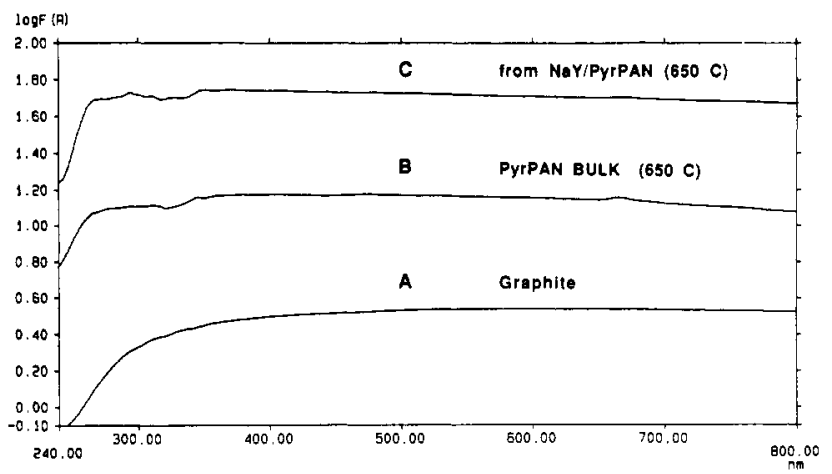

Figure 6. Electronic spectra of pyrolyzed PAN samples (Kubelka-Munk functions of reflectance spectra): (A) graphite; (B) pyrolyzed bulk PAN $\left(650^{\circ} \mathrm{C}\right) ;(\mathrm{C})$ pyrolyzed PAN extracted from NaY-PyrPAN $\left(650^{\circ} \mathrm{C}, 12 \mathrm{~h}\right.$ under vacuum).

no apparent external bulk polymer coating the zeolite crystals indicating that most of the polymer chains reside in the interior of the zeolite crystals. The pyrolyzed poly(acrylonitrile) extracted from $\mathrm{NaY}$-pyrolyzed $\mathrm{PAN}$ is insoluble in organic solvents; this suggests that the chain length is substantial even after pyrolysis.

In the FTIR spectra of the pyrolyzed zeolite/PAN samples (Figure 5), the methylenic stretching vibrations of the PAN main chain disappear, together with the characteristic nitrile band. New bands appear in the $1400-1600-\mathrm{cm}^{-1}$ region which have been assigned to $\mathrm{C}=\mathrm{C}$ and $\mathrm{C}=\mathrm{N}$ double bonds in the pyrolyzed bulk $\mathrm{PAN},{ }^{26}$ as well as the tail of the electronic excitation corresponding to free carrier absorption. In particular, for the extracted pyrolyzed polymer (Figure $5 \mathrm{C}, \mathrm{D}$ ), the band at $1596 \mathrm{~cm}^{-1}$ can be assigned to a mixed mode composed of $\mathrm{C}=\mathrm{C}$ stretching and $\mathrm{N}-\mathrm{H}$ bending, and the band at $1368 \mathrm{~cm}^{-1}$ is assigned to $\mathrm{C}-\mathrm{H}$ or $\mathrm{N}-\mathrm{H}$ in-plane bending.

For the bulk pyrolyzed samples, the IR reveals different degrees of graphitization depending on the pyrolysis temperature. A sample of bulk PAN heated to $530^{\circ} \mathrm{C}$ (Figure 5B) instead of $650^{\circ} \mathrm{C}$ shows more defined features in the $1400-1600-\mathrm{cm}^{-1}$ region, similar to the case of pyrolyzed PAN $\left(650^{\circ} \mathrm{C}\right)$ extracted from the zeolite, suggesting an early stage of graphitization. All the zeolite/PAN samples pyrolyzed at different temperatures, $\left(650,700^{\circ} \mathrm{C}\right)$, times $(12,24 \mathrm{~h})$, and atmospheres (nitrogen or vacuum) show spectra similar to the spectrum of bulk PAN pyrolyzed to $530^{\circ} \mathrm{C}$. This result suggests the ability of the zeolite channels to limit formation of an extended graphite-like structure.

The IR spectra of the extracted pyrolyzed PAN samples from zeolite $Y$ show a weak band around $3350 \mathrm{~cm}^{-1}$ assigned to NH groups (not shown). This band is broad and suggests the presence of some $\mathrm{H}$ bonding (from $=\mathrm{N}-\mathrm{H}$ ), indicating that the polymer extracted from the zeolite is not highly conjugated. The IR spectra of graphite and of bulk PAN pyrolyzed at $650^{\circ} \mathrm{C}$ (Figure 5A) show little discernible structure.

The electronic absorption spectrum (Figure 6) of pyrolyzed PAN extracted from $\mathrm{NaY}$ shows the appearance of a feature at about $350 \mathrm{~nm}$, as in the bulk, probably due to conjugated carbon-nitrogen double bonds in the ladder polymer. ${ }^{22}$ The rest of the spectrum is practically structureless and resembles the absorption spectrum of graphite (Figure 6A).

Composition and Structure of Intrazeolite Pyrolyzed Poly(acrylonitrile). In the unpyrolyzed poly(acrylonitrile) or in the polyimine ladder polymer the N/C atomic ratio is 0.33 . Bulk PAN pyrolyzed at $530^{\circ} \mathrm{C}$ retained an intermediate amount of nitrogen, $\mathrm{N} / \mathrm{C}=0.27$.
Table III. Conductivity Data for PAN Samples

\begin{tabular}{lc}
\hline \multicolumn{1}{c}{ sample } & conductivity, ${ }^{a} \mathrm{~S} \mathrm{~cm}^{-1}$ \\
\hline NaY zeolite & $\sigma \ll 10^{-8}$ \\
NaY-pyrolyzed PAN & $\sigma \ll 10^{-8}$ \\
pyrolyzed PAN bulk $\left(650^{\circ} \mathrm{C}\right)$ & $\sigma=1.2$ \\
pyrolyzed PAN extracted from & $\sigma=2 \times 10^{-5}$ \\
NaY-pyrolyzed PAN ${ }^{b}$ &
\end{tabular}

${ }^{a}$ Four-point probe measurements. ${ }^{b}$ Similar values were obtained for pyrolyzed PAN extracted from NaY-pyrolyzed PAN treated at different pyrolysis temperatures, times, and atmospheres.

In comparison, PAN heated in air at $220^{\circ} \mathrm{C}$ and subsequently in $\mathrm{Ar}$ at $600{ }^{\circ} \mathrm{C}$ for $8 \mathrm{~h}$ showed a $\mathrm{N} / \mathrm{C}$ ratio of $0.225 .^{22}$ In contrast, chemical analysis of the extracted pyrolyzed PAN derived from NaY-PyrPAN samples pyrolyzed to $650^{\circ} \mathrm{C}$ (vacuum, $12 \mathrm{~h}$ ) and $700^{\circ} \mathrm{C}$ (nitrogen, $12 \mathrm{~h}$ ) show $\mathrm{N} / \mathrm{C}$ ratios of 0.20 and 0.18 , respectively. These results indicate the formation of a conjugated structure during pyrolysis at $650^{\circ} \mathrm{C}$ in the zeolite host where about $50 \%$ of the nitrogen is already lost from the pyrolyzed polymer.

Thermal analyses under nitrogen of the zeolite-poly(acrylonitrile) inclusions show that the zeolite host drastically changes the pyrolysis reactions. Bulk PAN loses weight rapidly above $260^{\circ} \mathrm{C}$ (weight loss at $320^{\circ} \mathrm{C}, 16 \%$; at $700^{\circ} \mathrm{C}, 40 \%$ ), accompanied by a sharp exotherm at 260 ${ }^{\circ} \mathrm{C}$. In contrast, the zeolite inclusions show a much slower onset of decomposition with a broad exotherm (NaY-PAN, 245-315 ${ }^{\circ} \mathrm{C}$; loss between $250-700^{\circ} \mathrm{C}$ (after desorption of water), $50 \%$ based on initial acrylonitrile loading; $\mathrm{Na}$ MOR-PAN, $240-280^{\circ} \mathrm{C}$ exotherm; loss between $250-700$ $\left.{ }^{\circ} \mathrm{C}, 30 \%\right){ }^{32}$ These observations show that the zeolite host imposes kinetic constraints on the graphitization reaction of intrazeolite PAN.

After dissolution of the NaY host, $30 \%$ polymer was recovered based on the amount of monomer loaded into the zeolite. This yield corresponds to an average of 14 polymerized acrylonitrile units/zeolite unit cell. Zeolite $\mathrm{Y}$ is a cubic system with eight supercages (13- $\AA$ diameter) per unit cell and unit cell dimensions close to $25 \AA$. If each acrylonitrile unit in poly(acrylonitrile) cyclizes upon pyrolysis and forms a ladder polymer, then each unit forms one six-membered ring of about $6 \AA$ in diameter. Therefore, there must be enough space in each supercage of zeolite $Y$ for an average of at least 1.7 six-membered rings with the ladder polymer structure. It is unknown how these ladder systems are positioned in the zeolite, but the pore system provides enough space to accommodate the polymer.

For mordenite, the polymer recovery was $18 \%$. This value corresponds to approximately one molecule of acrylonitrile units per unit cell of mordenite. Mordenite has two channels per unit cell, with a unit cell dimension of $7.5 \AA$ in the $c$ direction along the main channels. Therefore, about 2.5 polyacrylonitrile or ladder polymer units can be accommodated per unit cell. This value is about twice as high as that based on the polymer recovered from the host. Thus, in mordenite, ladder polymer chains occupy at least every second one-dimensional channel per unit cell.

De Conductivity Measurements. Conductivity values measured with the four-point probe method are summarized in Table III. The absence of measurable conduc-

(32) The thermal analyses indicate substantial weight losses of the samples below $250^{\circ} \mathrm{C}$ that must be mostly due to zeolitic water (the polymer does not decompose below $260^{\circ} \mathrm{C}$ ); this shows that zeolite porosity is still maintained after formation of intrazeolite polyacrylonitrile. 
tivity in the $\mathrm{NaY}$ /pyrolyzed PAN samples is not suprising because the polymer is encapsulated completely within the insulating zeolite, and no external polymer coats the zeolite crystal surfaces. The conductivity of the pyrolyzed PAN extracted from the zeolite is almost identical with that of bulk PAN pyrolyzed at $530^{\circ} \mathrm{C}$, and 5 orders of magnitude smaller than that of the bulk sample pyrolyzed at $650^{\circ} \mathrm{C}$. In contrast to the bulk polymer, pyrolysis treatment conditions above about $600^{\circ} \mathrm{C}$ have little effect on the resulting conductivity of the intrazeolite samples. The same conductivity value of about $2 \times 10^{-5} \mathrm{~S} \mathrm{~cm}^{-1}$ is obtained for extracted pyrolyzed PAN, pyrolyzed at different temperatures, atmospheres, and times. It can be concluded that the spatial limitations within the zeolite channels prevent the formation of more extended, graphitized structures with higher conductivity.

\section{Conclusions}

Poly(acrylonitrile) was synthesized in the channel systems of $\mathrm{NaY}$ and $\mathrm{Na}$-mordenite zeolites and pyrolyzed to yield a conducting material. Before pyrolysis, the intrazeolite polymer has a random configuration as in the bulk, and extends through a significant part of the $\mathrm{NaY}$ zeolite crystals, while polymerization in the one-dimensional channels of mordenite produces much shorter chains. Upon pyrolysis, conjugated ladder polymers are formed which show conductivities in the semiconductor regime when extracted from the zeolite hosts. A striking feature of these pyrolyzed polymer inclusions is the strong limiting effect of the zeolite structure on the degree of ring closure and graphitization. As expected from the channel dimensions, complete graphitization with formation of extended sheetlike structures is not possible in the zeolite; instead, the pyrolysis reactions are limited to the ladder structures formed in the bulk at lower temperature. Future work will explore the effect of larger pore sizes on polymerization and graphitization of acrylonitrile inclusions and their associated electronic conductivity. These systems are promising candidates for low-field conductivity at nanometer scale dimensions.

Acknowledgment. We acknowledge partial funding for this work by Sprague Electric Co. We thank Bill Ackerman (UNM) for performing the thermal analyses and R. Ju for chemical analysis of the samples.

Registry No. PAN, 25014-41-9.

\title{
Induction of Noncentrosymmetry by Polar Hydrogen-Bonded Chains in Nitroaniline Crystals
}

\author{
Margaret C. Etter* and Kin-Shan Huang \\ Department of Chemistry, University of Minnesota, Minneapolis, Minnesota 55455
}

Received December 10, 1991. Revised Manuscript Received March 13, 1992

\begin{abstract}
The role of polar hydrogen-bonded nitroaniline chains in inducing noncentrosymmetry in bulk nitroanilines is explored here using correlations between the presence of such motifs and the occurrence of noncentrosymmetric space groups among all known nitroaniline crystal structures. Our results show a significant bias for compounds with polar nitroaniline motifs to have noncentrosymmetric structures (46\% of 24 structures) compared to the frequency with which achiral molecules in general form noncentrosymmetric crystal structures (11\%). Thus, the special role that nitroanilines have played in the field of organic nonlinear optical materials may be attributed not just to their normally large hyperpolarizabilities but also to the fact that this class of molecules has an unusually high tendency to form noncentrosymmetric crystals.
\end{abstract}

\section{Introduction}

We are seeking to understand what features of noncentrosymmetric crystal structures are controllable and what features correlate with the absence of centers of symmetry, a necessary constraint for second-order nonlinear optical materials. The problem is that controlling any feature of a crystal packing pattern is a formidable task. This task would be much simpler if the mechanisms of organic crystal nucleation and propagation were better understood, especially at the molecular level. From our recent work on the use of hydrogen bonds to control cocrystal formation, ${ }^{1}$ we have begun to view the crystal growth process as one that involves a preassembly step whereby hydrogen-bonded sets of molecules form in solution. ${ }^{2}$ These aggregates are thought to then nucleate

(1) Etter, M. C. J. Phys. Chem. 1991, 95, 4601.

(2) Etter, M. C.; MacDonald, J. C.; Wanke, R. A. J. Phys. Org. Chem., in press. crystal growth while retaining their hydrogen-bond connectivity patterns. Our previous analysis of nitroaniline crystal structures, showing the presence of recurring polar hydrogen-bonded nitroaniline chains, is consistent with the idea that the nitroaniline chains themselves, rather than individual molecules, are the prenucleation sites for crystal growth. ${ }^{3}$ With this perspective in mind and with the realization that nitroaniline chains are necessarily noncentrosymmetric, ${ }^{3}$ we questioned whether these chains could be inducing nitroaniline compounds to grow as noncentrosymmetric crystals. In other words, despite the favorable hyperpolarizability properties of nitroanilines, are they better than normal candidates for nonlinear optical uses because they are more likely than usual to be noncentrosymmetric? This question is addressed here using data retrieved from the Cambridge Structural Da-

(3) Panunto, T. W.; Urbañczyk-Lipkowska, Z.; Johnson, R.; Etter, M. C. J. Am. Chem. Soc. 1987, 109, 7786 . 